\title{
When time flowed \\ The Story of the Clepsydra
}

\author{
BY
}

\author{
John S. McNown
}

Professor of Civil Engineering

University of Kansas,

\section{Early Developments}

Before the advent of the mechanical clock in the 13 th century, our ancestors depended upon both sun dials and water clocks for the telling of time. Sun dials are still well known. Water clocks are far less so and yet also have an intriguing history. They were developed as a complement to systems for telling time by the sun and the stars. They could function indoors and in cloudy weather when sun dials were useless. An inscription sometimes used on sun dials

$$
\text { "I tell none but the sunny hours" }
$$

is both a cheerful harbinger of good weather and an admission of weakness. Sun dials were surely more practical in sunny Egypt than in the cloudy climes of northern Europe.

Water clocks are known as clepsydrae, the word coming from Greek words meaning to steal water. The first syllable is like that in the word kleptomaniac. The elemental clepsydra worked like an hour glass and was considered "a thief of water". The period required for an amount of water to escape through a small hole in a vessel was a measure of time. Some clepsydrae had the heroic size of public fountains, others were portable. Some were ornate and served as gifts for kings and emperors, some were small and are sometimes referred to as stop watches. The King of Persia gave Charlemagne an elaborate silver water clock in $807 \mathrm{AD}$. It has twelve small doors. Every hour one of them opened and released its quota of small metal balls, the number of balls being equal to the hour. The balls sounded the hour as they fell one after the other onto a brass drum. At 12 o'clock a mounted horseman appeared and closed the doors.

Clepsydrae may be as old as sun dials. Both devices have been used for thousands of years. The oldest water clock to have been found in good shape was used in upper Egypt about $1400 \mathrm{BC}$ (Fig. 1). Even that long ago, its shape showed progress beyond the simple vessel with a hole in it. Earlier ones in Chaldea and Egypt have been referred to, but their earliest use is lost in pre-history. Later, they formed a part of the daily and artistic lives of the Greeks and Romans. Remains of one elaborate structure can still be seen in Athens. Ctesibius designed and built it in the third century $\mathrm{BC}$, and Vitruvius described it in his voluminous writings.

Priests and others had an interest in foretelling the seasons and in setting the dates of festivals. A few of these people had also the time and the learning to develop an understanding of the motion of the sun and the stars through the night and throughout the year. But their observations suffered from a lack of accurate measurem-

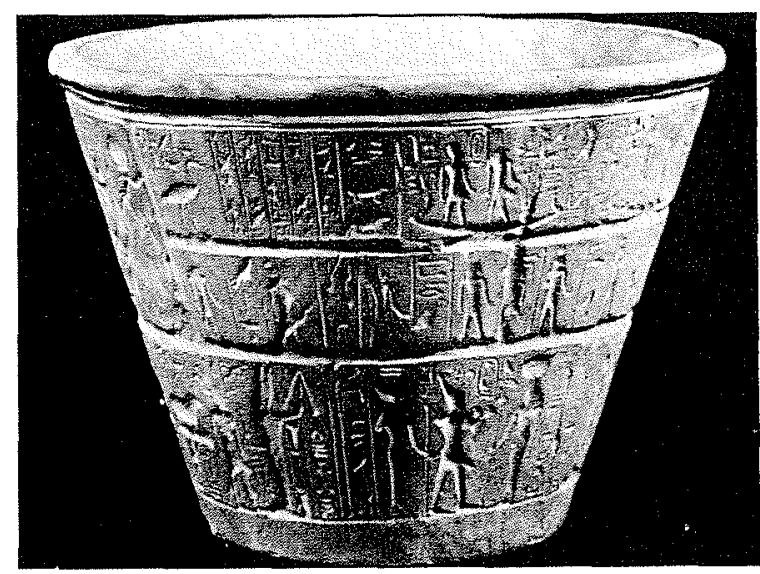

$1 /$ Oldest known clepsydra is the Karnak bowl from $1400 \mathrm{BC}$. 
ents of time. The sun, with or without a sun dial, gave only a rather crude indication of time during the day, and the stars served in the same manner at night. Both were limited in accuracy by the slowness of the turning of the earth and the lack of astronomical instruments. The clepsydra, being independent of the earth's motion, was a more flexible instrument.

Pompeii decreed the use of a water clock to limit the length of speeches of Roman orators. Julius Caesar used one to note that the summer nights in Great Britain were shorter than those in Rome. Time keepers used them to control the hours that slaves must work and the length of the military watch. An inscription on an early one read

"... to determine the hours of the night when the stars are invisible. . "

and

\section{"Thus the correct hour of the sacrifice can} be observed..."

Doctors in medieval times used small clepsydrae to time the pulse rates of their patients. Many a town depended upon a large clepsydra in a central place to regulate the daily cycle of urban life. Tycho Brahe used one for his astronomical work. Clepsydrae monitored much of our past

\section{Types Used in Ancient Times}

The first clepsydra was probably a unit timer like the hour glass and the egg-timer. The one used to restrain the loquacious Romans was a brass bowl with a small hole in the bottom. It was floated on a larger container of water at the beginning of the speech, and as time passed, water seeped through the hole into the bowl. When the bowl filled and sank, time was up! Some senators were reported to have bribed the time keepers to put a little dirt in the opening so as to reduce the rate of flow and lengthen the time for their speeches. The system was soundly based on fluid mechanics, but it was not safe from tampering. An old sinking bowl from the time of the druids indicated its use near City Antrim in Ireland before the Roman invasion.

Later, people wanted to measure the parts of the day without resorting to counting such intervals of time. They needed a clock rather than a timer. The simplest clepsydra and probably the first was a vessel with a hole near the base. It had one serious drawback as a clock. Because the rate of flow from a vessel varies as the depth of the water decreases, the water level in the vesse ${ }_{1}$ is not simply related to the time. The process of subdividing the hours was not a simple matter, particularly during an epoch long before Torricelli and Bernouilli. The velocity of efflux, as Torricelli showed in the 17 th century, varies with the square root of the depth or head.

$$
V=\sqrt{2 g h}
$$

in which $g$ is the acceleration of gravity. The product of this velocity and the area of the jet is the rate of efflux from the vessel.

The falling of the free surface also depends upon the shape of the container. If the container is a cylinder, the interval of time for the level of the free surface to drop from $h_{1}$ to $h_{2}$ is given by the equation,

$$
t_{2}-t_{1}=\mathrm{K}\left(\sqrt{h_{1}}-\sqrt{h_{2}}\right)
$$

in which the ratio of the area of the opening to the area of the free surface, the value of $g$ and various constants are combined in the factor $K$. If the initial depth were just 9 times the final one, the hours for such a clock would be spaced as shown in Figure 2. The water level would fall three times as fast at the beginning as it would at 12 o'clock.

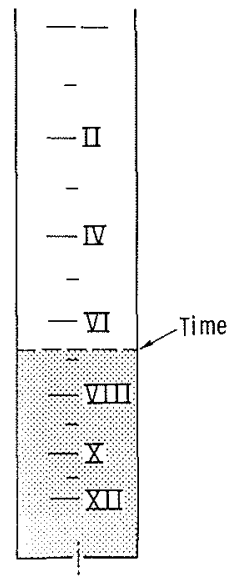

2/ Hour spacing varies for a cylindrical out-flow clepsydra.

\section{Linearized Systems}

Ancient clock makers were dissatisfied with the nonlinear system shown in Figure 2, much as we would be today. Inevitably, they sought to improve it. The use of containers whose cross-sectional area was smaller at the bottom than at the top, like the Karnak bowl, may have been an early attempt to achieve a more nearly linear rate of settlement. The decrease in the area of the water surface with decreasing head tends to compensate for the reduction in flow rate. If the cross-sectional area is directly proportional to the rate of outflow, the rate of fall will be constant. Since the area is proportional to $r^{2}$ and the velocity is proportional to $\sqrt{y}$, the perfect bowl would be shaped so that its depth and radius follow the equation

$$
y=k r^{4}
$$

The early clock makers may have avolded this problem through good fortune ; the shapes of many ancient pots, and of modern kettles too, do not differ greatly from that given by Eq. (3) and displayed in Figure 3.

With neither the requisite theory nor an independent method of timing, early designs could only approximate the ideal shape. The clepsydra of Karnak was undoubtedly such an approximation. Its shape is compared with the quartic curve in Figure 3. The two are so close to each other that the result must be more than coincidence. However, even though the geometric differences are quite small, they still account for timing errors which may have delayed the development of Egyptian astronomy. A comparison of the rates of settlement for the two was based on shapes with equal volumes of water and equal total times, and on the assumption that the bottom tenth of the bowl was not used. The designers' concern for achieving a linear 
rate of descent would surely have made them aware of the large departures which occurred as the depth in the conic frustum approached zero. For these conditions the Karnak bowl would have been nearly 20 minutes slow about 40 clock, right on time at 9:30, 4 minutes ahead at 11 and correct at 12 as shown to the right in Figure 3.

Quite a different technique for achieving linearity depended upon producing a constant rate of flow outside of the container or measuring bowl. The system was reversed with the clock reservoir being the receptacle of this inflow. The supply of water was regulated as in Figure 4 through use of a constant-head device or trop plein, much as we do today. The cylindrical container would then fill at a constant rate. A float riding on its free surface would then indicate time on a suitable linear scale.

A third system achieved linearity through use of floating devices. One was the siphon shown in Figures 5 and 6 . Since both ends of the siphon move, the rate of flow is independent of the level of water in the container, and the rate of descent is constant. The Roman orators' floating container with the hole in the bottom, Figure 7, also used flotation to maintain a constant head. No matter how full or empty the bowl, the difference between

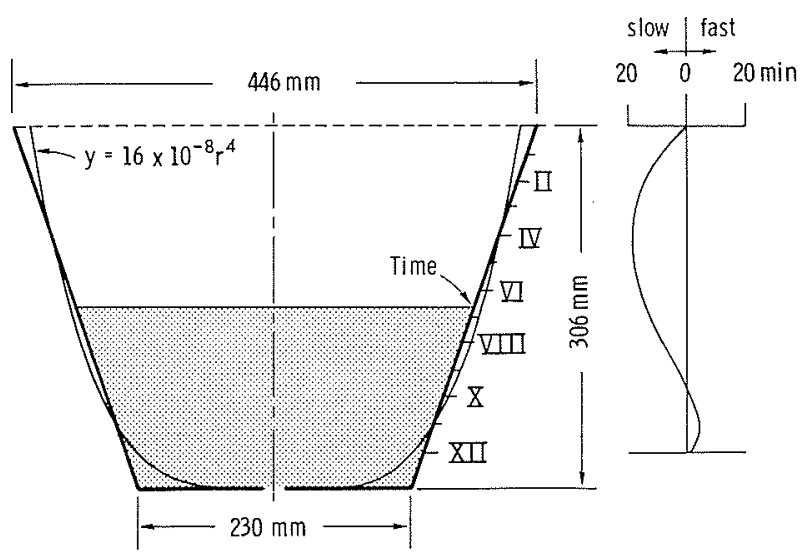

3/ Karnak bowl approximates ideal shape for linear decrease in water level.

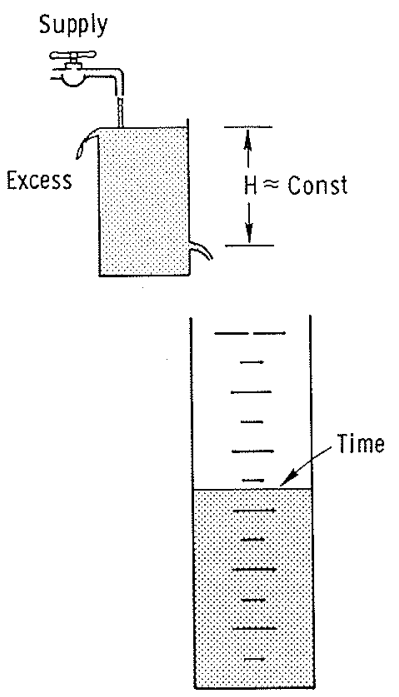

4/ Constant-level device provides constant inflow.

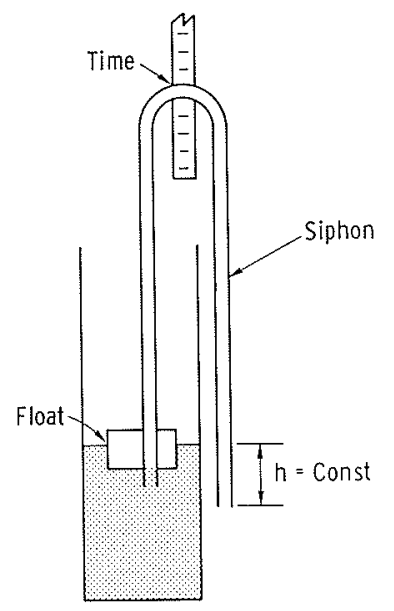

5/Constant head achieved with floating siphon.

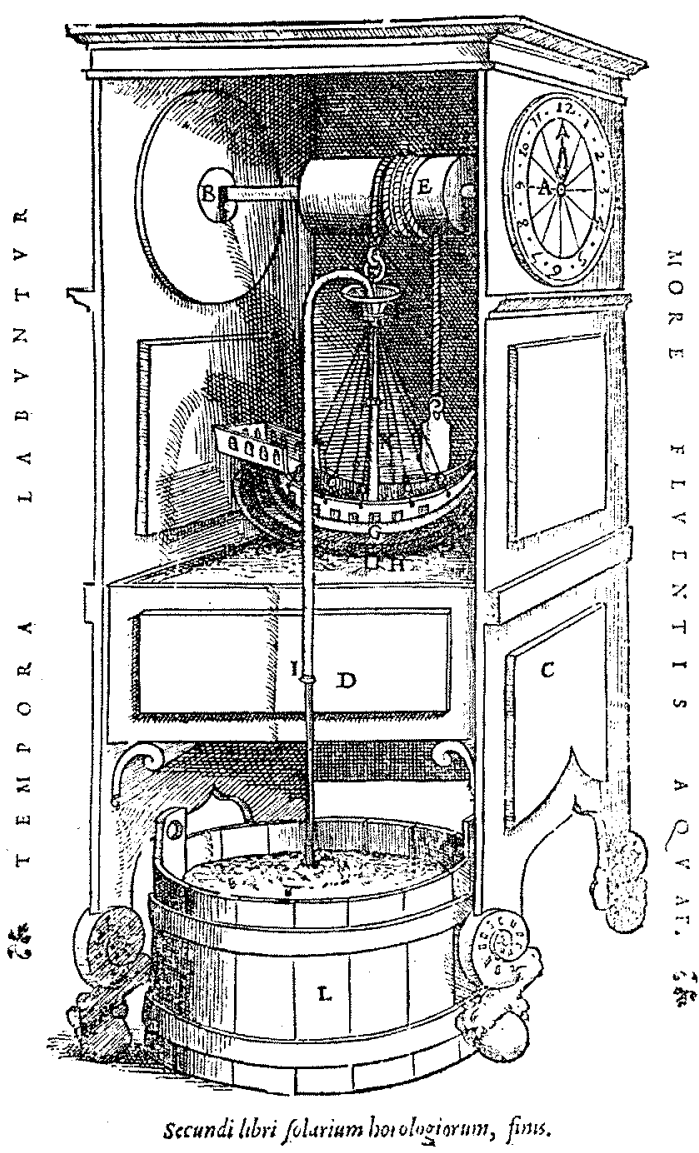

$6 /$ Siphon carried by ornate ship.

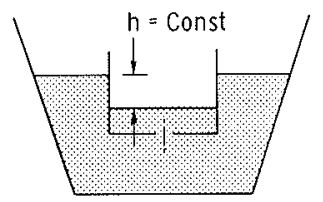

7 /Bowl floats as it sinks 
the levels of water inside and out must be sufficient to support the container through buoyancy. Thus a cylindrical bowl with thin walls would settle at a constant rate.

\section{Other Early Devices}

The device shown in Figure 8 was probably never built, at least not as shown. The system is inherently non-linear so that the spacing of the hours would necessarily be variable. The out-flow per unit time varies with the square root of the head, with a result like that for the clepsydra shown in Figure 2. The combined weight of the container and water is counterbalanced by a weighted rope. As the water runs out, the bucket becomes lighter ; it then rises gradually as the counterweights on the rope pile up on the floor. The principle is sound, and the technique of counterbalancing is novel. Either the spacing of the hours must decrease as time passes, or the spacing of the weights on the rope must correspond to the rate of flow.

Frequently the movement of the free surface was translated into a rotary one either by means of an axle as in Figure 6 or a rack and pinion. Thus, a pointer on the end of the rotating shalf could be arranged so as to indicate the time on a 12-hour clock face like those of today. Some clocks had striking devices to count the hours, special forms of illumination for night use and gear arrangements of various sorts. Some even had an escapement mechanism. Thus various aspects of present-day clocks developed before the mechanical clock with which we associate them.

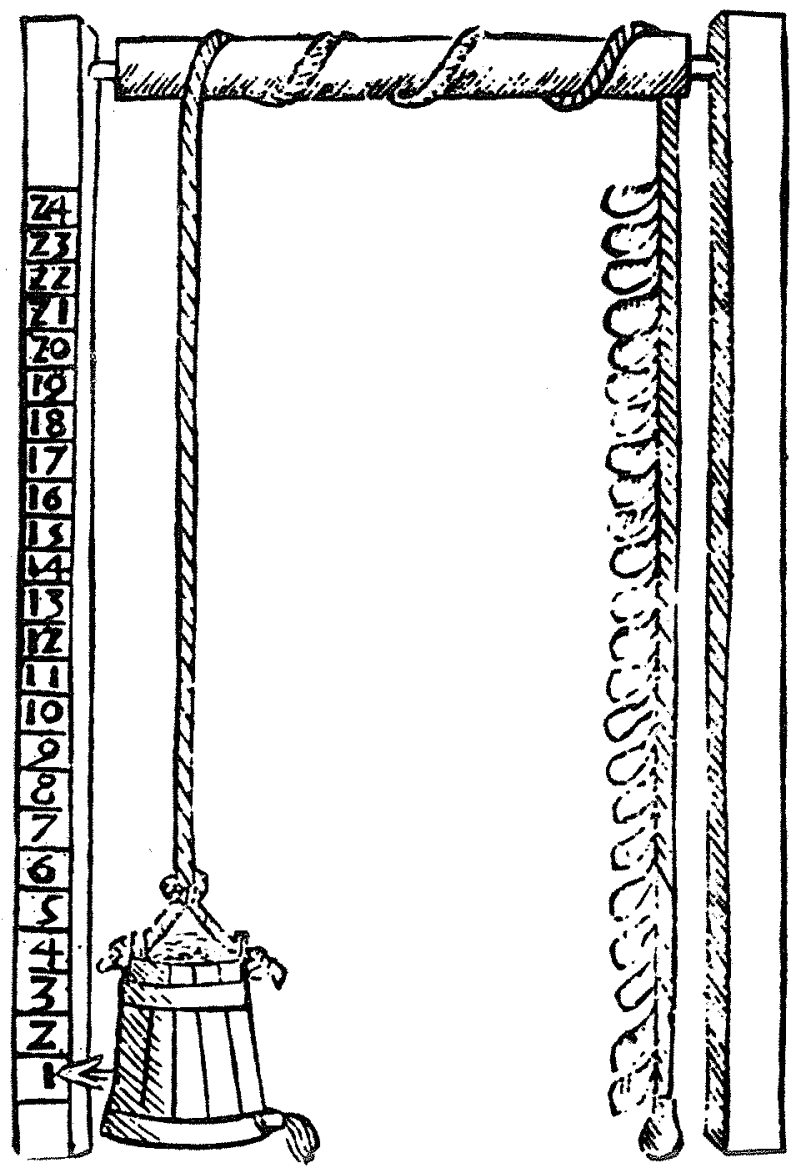

8/Out-flow bowl suspended by a rope with counterweights.
An additional hydraulic device made by Ctesibius was one of the first feedback systems ever made, perhaps the first. He equipped his clepsydra with a siphon. When the water in the cylinder was full, the siphon would fill and begin to flow. The cylinder would then empty itself quickly and automatically. Once the container was empty the siphon would break and the cycle would begin again. In principle, it would function unattended as long as it received its supply of water.

Good performance of clepsydrae required that the size of the opening through which the water ran remain constant over a long period of time. If it eroded during prolonged use, the clock would run fast. If deposits formed on it, the clock would run slow. Vitruvius wrote that Ctesibius used

"an orifice in a piece of gold, or by perforating a gem, because these substances are not worn by the action of water, and do not collect dirt so as to get stopped up".

The ancients were also confronted by a complication which no longer concerns us. The lengths of their day and hour varied with the seasons. The day was the time between sunrise and sunset, and the hour was one twelfth of a day. Both varied with the length of the period of daylight. They varied less in Egypt than in Scotland, but even in Greece and Rome, the long days of summer were nearly three of our hours longer than the short days of winter. Their hour thus varied from 53 to 67 modern minutes. A good clepsydra was required to have adjustments with which it could be made to reflect such changes. The most imaginative ones, including that of Ctesibius, made the changes automatically, and many had illustrations and controls which were marked by the astrologers' signs and constellations.

\section{The Chinese Stair Step Clock}

The Chinese developed a technique for linearizing the clepsydra which never appeared in the western world. In early historic times they also used the familiar bowl from which water leaked through a small hole. But from about $200 \mathrm{BC}$ on, they turned to systems in which water flowed into a cylindrical container. A rod riding on a float indicated the time by its upward travel. They made the inflow constant in one of two ways: the first was the familiar overflow device to achieve constant head, and the second, the novel type, consisted of a series of identical bowls arranged in the stairstep formation shown in Figure 9. All bowls but the last were filled initially so that the flow coming into each bowl just compensated for the flow out. If several bowls were used, the effect on the linearity of outflow for the lowermost bowl was remarkable, as can be shown analytically.

The equation of continuity for the $n$th bowl, counting in the direction of flow as in Figure 10, is

$$
A \frac{d h_{n}}{d t}=Q_{n-1}-Q_{n}
$$

and the discharge $Q_{n}$ is given by

$$
Q_{n}=C a \sqrt{2 g h_{n}}
$$




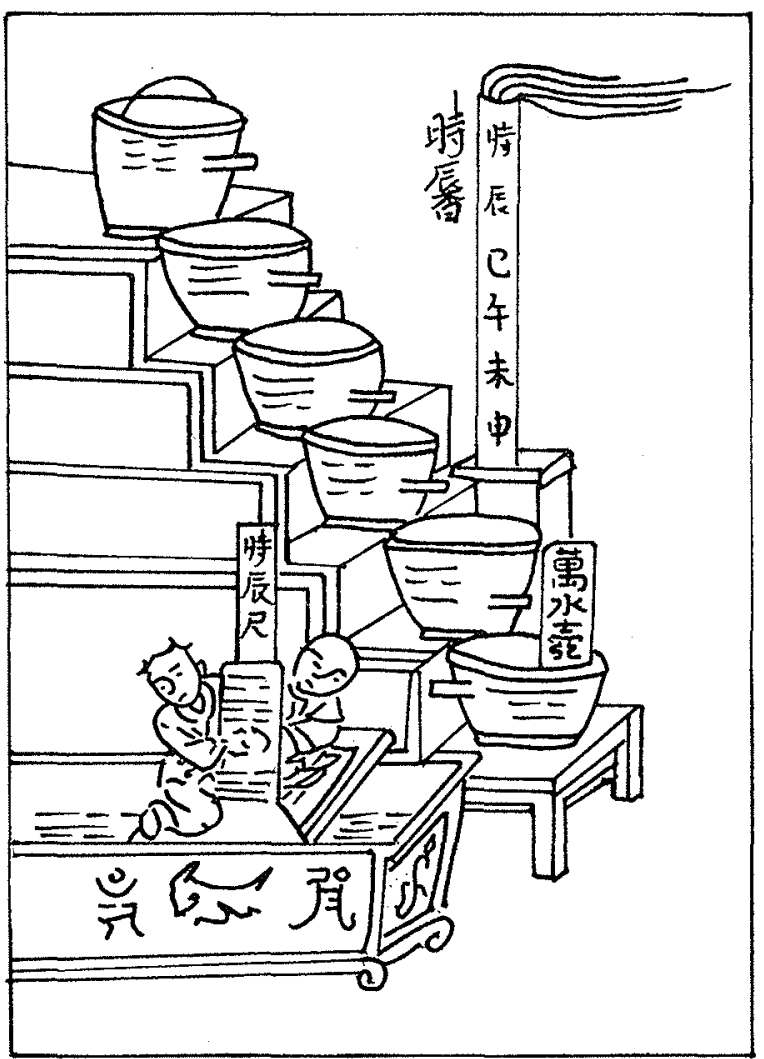

9/ Chinese stair step clock

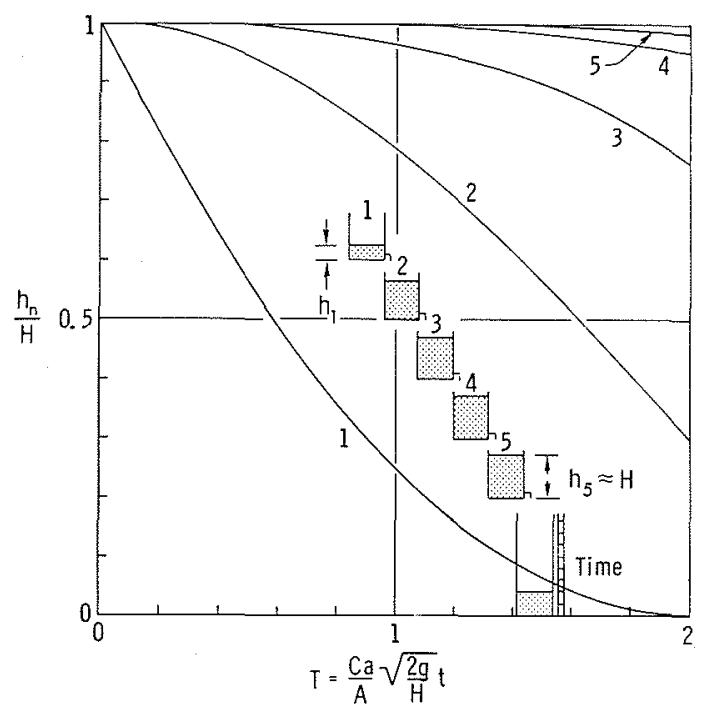

$10 /$ Constancy of flow depends upon number of bowls.

$A$ is the area of the water surface in the bowl, $a$ the area of the opening and $C$ the coefficient of discharge. The combination of Eqs. (2) and (3) yields the difference equation

$$
\Delta \frac{h_{n}}{H}=\left[\sqrt{\frac{h_{n-1}}{H}}-\sqrt{\frac{h_{n}}{H}}\right] \Delta T
$$

in which $H$ is the inital head in all $n$ reservoirs and $T$ is the dimensionless time

$$
T=\frac{C a}{A} \sqrt{\frac{2 g}{H}} t .
$$

The variation of the head with time can be obtained for any reservoir by means of step calculations beginning with the known variation in the upper-most reservoir. Since $Q_{\mathrm{o}}=0$, Eqs. (4) and (5) yield the explicit solution

$$
\frac{h_{1}}{H}=\left(1-\frac{T}{2}\right)^{2}
$$

If this result is substituted in Eq. (6), the variations of $h_{2}$, and then $h_{3}, \ldots h_{n}$ with time can be determined.

An approximate analysis can be made using firstorder terms only. It is based on Eq. (6), but with

$$
\Delta\left(h_{n} / H\right)=1-\left(h_{n} / H\right)
$$

on the left side and $h_{n} / H=1$ on the right. The result is

$$
\frac{h_{n}}{H}=1-\frac{T^{n}}{2^{n-1} n !}
$$

Calculations based on Eq. (7) are quite close to those from Eq. (6) if $T$ is small or $n>2$. The results are shown in Figure 10. The striking feature of the curves is the constancy of $h_{n} / H$ with time for $n>4$. At $T=2$, the time at which the uppermost reservoir becomes completely empty, the level in the fourth reservoir is down by $H / 12$, and that in the fifth by only $H / 60$. The people who made the containers probably had more difficulty making them identical then they did in achieving constancy of head in principle by this technique. The method of operation was simple. A servant took water from the lowermost reservoir from time to time and used it to top-up the upper ones as they drained. The set with six bowls shown in Figure 9 was copied from an old drawing. Such sets were often used in China both in pre-clock days and in more recent times.

\section{A Modern Clepsydra}

The most ingenious clepsydra of all was quite unlike any of the others. It was devised more recently as it probably came into use in the 11 th century. It was inherently linear and self-contained, and it could be rewound as simply as a weight-driven mechanical clock. Its moving element was a drum-shaped container which was divided into a number of compartments, as shown in Figures 11, and 12, and half-filled with water or, for smaller ones, with mercury. The drum was supported by cords wound around the axle on which the drum was mounted, and the entire system hung from a frame. The cylinder would simply unwind because of its unbalanced weight torque except for the fact that, as it began to turn, the liquid moved to one side and provided a counter-balancing torque. The compartments were interconnected by small holes, and as the liquid was raised to one side, the difference in levels caused it to seep slowly from one compartment to the next. With this flow, the cylinder descended slowly and at a constant rate. The vertical position of the axle marked the time, and marks on the periphery of the cylindrical drum indicated shorter periods.

Variants of the drum clock are shown in Figure 13. In one, a counterweight moves and the drum rotates about a fixed axis. Time is indicated either by the vertical position 

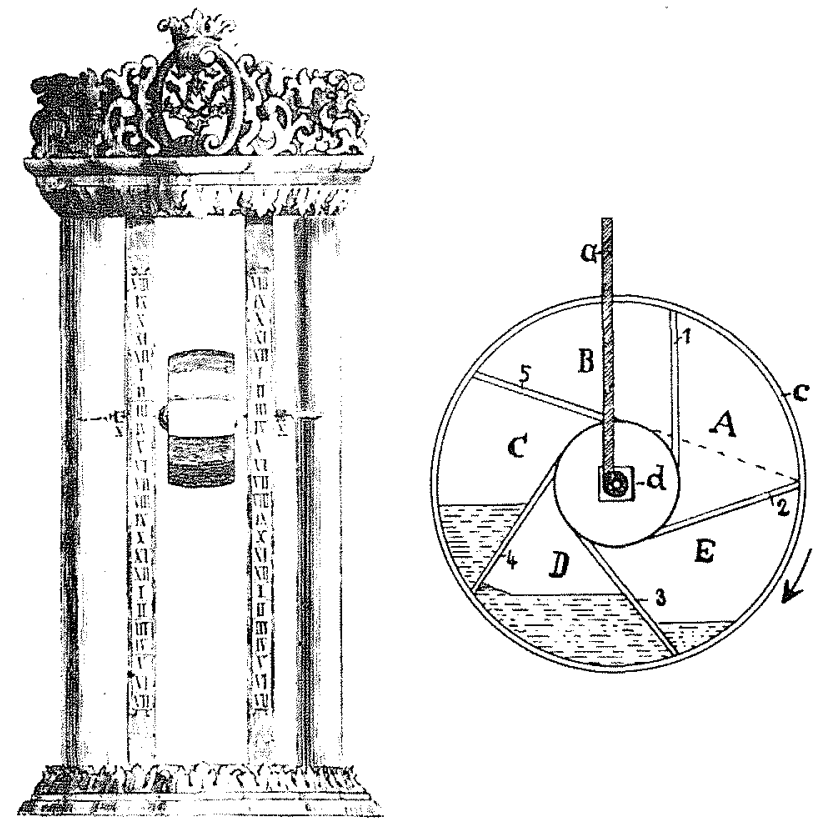

11/ Falling drum from the Middle Ages.

of the weight or by the angular position of the drum. The counterweight was easy to change if the clock ran fast or slow. In the other, the drum rolls slowly on its axle down inclined tracks. The motivating force is the component of the weight, and the internal motion of the fluid controls the rate of descent as in the other drum clocks. Such a device could be adjusted by raising or lowering one end of the track, and the drum could be easily moved from the lower end to the upper one to start the day without the need for an adjustment corresponding to a fraction of a revolution.

The use of the drum clock was sporadic. It appeared at different times in Spain and Italy and France, and then disappeared from historical view again. Only a few records of the early clocks exist, and none of the original clocks themselves. Copies were made and sold as curios in the 19 th century. The prevalence of these "new" old clocks and the scarcity of the genuine article led some writers to suggest that the clock had not existed at the time it was reputed to have been in use. Others placed its discovery in the 17 th century. Bedini, however, has documented its description in an astronomical compilation prepared for King Alfonso $X$ in Toledo about 1277. In it the author stated that the Arabs had developed the device some two hundred years earlier. Similar clocks that reappeared centuries later in Italy and France were probably based on knowledge of the original Spanish treatise. The device was a remarkable one and served a limited market for some centuries. Even when mechanical clocks became available, they were far too complex and difficult to make for general use. Some form of clepsydra was more practical, and the drum clock was the best of these.

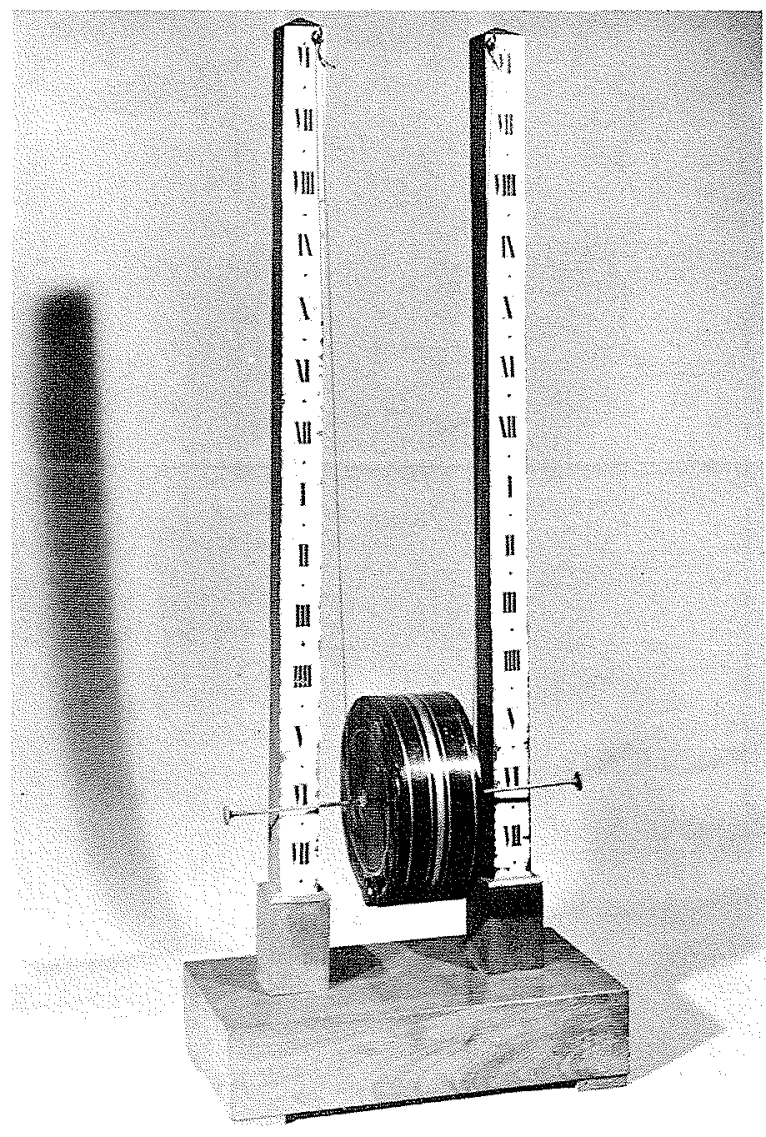

$12 /$ Falling drum (Musée des techniques - CNAM)
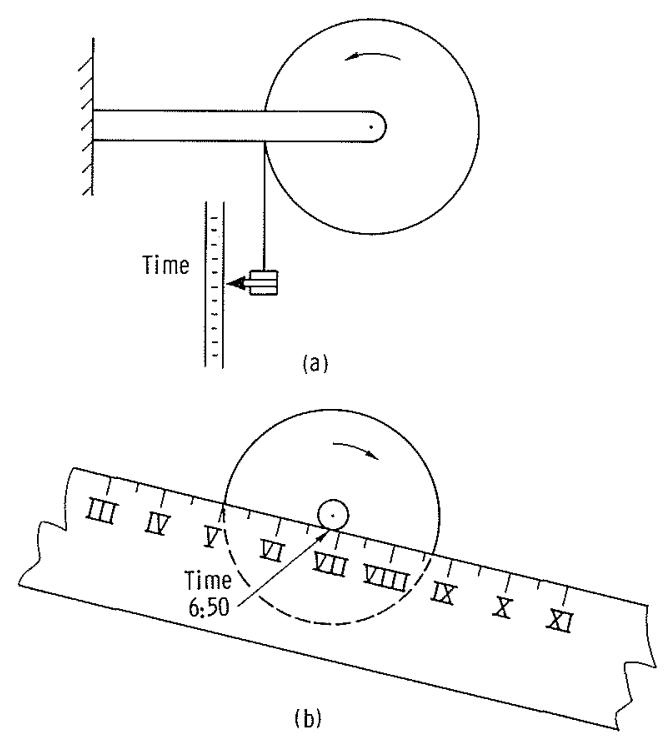

$13 /$ Variations of falling drum include (a) fixed axis and (b) inclined track

\section{The Clepsydra Disappeared}

But where have clepsydrae gone? Hour glasses continue to appear on curio shelves. Father time usually carries one. Sun dials often decorate gardens, and campers and explorers carried them in recent times as emergency equipment. Rows of books on library shelves present the requisite solar astronomy and describe methods of con- 
structing them. In contrast, water clocks have virtually vanished, leaving behind only an occasional museum copy and a few pages here and there in histories of time measurement. Few people recognize the word clepsydra, and even fewer know that the elementary water clock worked like an hour glass rather than a water wheel.

Yet they have been used in modern times. The sinking bowl has served recently in Algeria to measure the period of time for irrigation water to flow onto a farmer's field. The Chinese stairstep clock is mentioned in Chinese history, and travelers have reported its use in remote areas within the last century. A few of the 19 th century copies of the drum clock are on display in museums. Perhaps they will come into vogue again one day. Hydraulicians, particularly, should support these ecologically satisfactory, energy-conserving devices which portray so picturesquely carly recognitions of the principles of fluid mechanics.

\section{Bibliography}

BEDINI (S.A.) - "The Compartmented Cylindrical Clepsydra", Technology and Culture, Vol. 3, 1962, pp. 115-141.

London, Science Museum, Handbook of the collections illustrat ing time measurement, 1967.

LUBKE (A) - Die Uhr, von der Sonnenuhr zur A tomuhr.

NeEDham (J.), WANG LING and PRICE (D.) - Heavenly Clockwork, Cambridge, 1960.

UNGERER (A.) - Les horloges astronomiques, Strasbourg, chez l'auteur, 1931.

VITRuvius - The Ten Books on Architecture, Chap. VIII, Book IX, transl. by M.H. Morgan, Harvard Univ. Press, 1914.

WiNs (A.) - L'horloge, a travers les äges, Paris, Libr. Edouard Champion, 1924. 